УДК 101.1

$10.17213 / 2075-2067-2020-3-133-140$

\title{
О НЕКОТОРЫХ ТЕНДЕНЦИЯХ ОБЩЕСТВЕННОГО РАЗВИТИЯ РОССИИ В СВЯЗИ С ПАНДЕМИЕЙ КОРОНАВИРУСА
}

\author{
(C) 2020 г. И. Н. Алексеенко*, Г. А. Воробьёв **, С. И. Самыгин *** \\ *Донской педагогический колледж, г. Ростов-на-Дону, Россия \\ **Пятигорский государственный университет, г. Пятигорск, Россия \\ ***Ростовский государственный экономический университет (РИНХ), \\ 2. Ростов-на-Дону, Россия
}

Цель данной статьи состоит в рассмотрении аспектов и тенденщий общественного развития России на современном этапе в связи с пандемией распространения новой коронавирусной инфекции.

Методология исследования базируется на традиџиях трансдисииплинарной социальной философии, на идеях архаизации В.Г. Федотовой и конщееции Ч.К. Ламажаы, рассматривающей российскую архаизацию в качестве адаптивной реакции на структурные изменения.

Результаты. Одной из актуальных проблем в рамках сочиальных наук является проблема соотношения модернизаџии и архаизаџии как двух сторон процесса социальной трансформаичи российского общества. В настоящее время особую научную и практическую значимость данная проблема приобретает в связи с глобальной пандемией новой коронавирусной инфекции и введением режима самоизолячии среди всего населения России. В результате проведенного анализа авторы приходят к выводу, что реакция и меры государства на ситуацию с коронавирусом подтверждают действие в России неопатримониального политического режима, который блокирует процесс модернизаџии общества и ведет к архаизащии.

Ключевые слова: общественное развитие; российское общество; социальная трансформация; идеология; модернизация; архаизация; пандемия.

\section{ON SOME TRENDS IN THE SOCIAL DEVELOPMENT OF RUSSIA IN CONNECTION WITH THE CORONAVIRUS PANDEMIC}

\author{
(C) 2020 I. N. Alekseenko*, G. A. Vorobiev**, S. I. Samygin*** \\ *Don Pedagogical College, Rostov-on-Don, Russia \\ **Pyatigorsk State University, Pyatigorsk, Russia \\ ***Rostov State University of Economics (RSUE), Rostov-on-Don, Russia
}

The purpose of this article is to examine the aspects and trends of social development in Russia at the present stage in connection with the pandemic spread of a new coronavirus infection.

The methodology is based on the transdisciplinary tradition of social philosophy, the ideas of archaism of V. G. Fedotova and concepts of Ch. K. Lamazhaa, considering Russian archaic as an adaptive response to structural changes.

Results. One of the most pressing problems in the social Sciences is the problem of the correlation between modernization and archaization as two sides of the process of social transformation of 
Russian society. Currently, this problem is of particular scientific and practical significance in connection with the global pandemic of a new coronavirus infection and the introduction of a regime of self-isolation among the entire population of Russia. As a result of the analysis, the authors come to the conclusion that the reaction and measures of the state to the situation with coronavirus confirm the action of a non-patrimonial political regime in Russia, which blocks the process of modernization of society and leads to archaization.

Key words: social development; Russian society; social transformation; ideology; archaization; pandemic.

Введение. В последние десятилетия в российском обществе мы наблюдаем трансформационные процессы, которые начались в конце XX века под лозунгами формирования демократических политических институтов, рыночной экономики и утверждения либеральных ценностей. Действительно, в 90-хгг. XX века был заложен институциональный фундамент для демократического режима, который практически сразу стал обрастать неформальными практиками, деформирующими сущность данного режима. Развитие рыночной экономики в России носило столь же противоречивый характер. Ход реформ и их результаты вызывали недовольство большой части российского общества, которая восприняла эти реформы как причину ухудшения своего социально-экономического положения. Недовольство естественным образом стимулировало ностальгические настроения, возвращая население к идеализированному прошлому.

В связи с этим одной из актуальных проблем в рамках социальных наук является проблема соотношения модернизации и архаизации как двух сторон процесса социальной трансформации российского общества. Актуальность данного вопроса обусловлена противоречивостью реальных процессов, порождаемых переходом современных обществ в новое экономическое, политическое и социокультурное пространство. В настоящее время особую научную и практическую значимость данная проблема приобретает в связи с глобальной пандемией новой коронавирусной инфекции и введенного режима самоизоляции среди всего населения России.

Общей теоретической рамкой данной статьи служит концепция модернизации, причем как классический ее вариант, так и возникшая позже концепция множественности модерна или множественности современностей, получившая популярность в последние годы. Мы полагаем, что, обогащая классическую концепцию модернизации идей значимости культурных различий и их воздействия на ход модернизации, концепция множественности модерна не меняет существенно смысл классической концепции. Несмотря на видимую вариативность, модерн все же подразумевает определенный набор институций и культурных черт, без которых говорить о модернизации невозможно [1]. Иными словами, модернизация вариативна, но имеет некоторое сущностное ядро.

Труды и идеи многих исследователей, работающих в социально-гуманитарном направлении, в большей степени редуцируются к выводу, что современное российское общество, несмотря на растущую информатизацию и широкое включение в глобальные процессы, крайне ошибочно было бы понимать как сугубо модернизированное [2]. Это объясняется тем, что реакция общества на трансформационные процессы бывает консервативной, да и многие внешние изменения со стороны государства опираются на архаизм [3, 4].

Одним из первых проблему архаизации применительно к российскому обществу исследовал А.С. Ахиезер, который в своих трудах показывал, что российское общество на протяжении долгих веков своей истории функционирует как расколотое, регулярно отвечая на вызовы нового и структурное усложнение реакциями упрощения, возврата к более простым моделям [5].

В рамках данной работы мы обращаемся к политической составляющей российской архаизации в связи с проблемой патримо- 
ниальных и неопатримониальных режимов $[6,7]$. Значительный вклад в анализ проблемы архаизации внесла В.Г. Федотова [8]. Концепция, разработанная Ч.К. Ламажаа, рассматривает российскую архаизацию в качестве адаптивной реакции на структурные изменения, и в рамках данной концепции архаизация рассматривается преимущественно на региональном примере [9].

Цель данной статьи состоит в рассмотрении аспектов и тенденций общественного развития России на современном этапе в связи с пандемией распространения новой коронавирусной инфекции.

Общественное развитие России и проблемы архаизации. Говоря о социальных проблемах, вызванных в результате распространения новой коронавирусной инфекции, мы можем заметить активное обращение со стороны государственных органов к архаике.

Мы можем обнаружить проявления архаизации как на уровне повседневного, обыденного существования, так и на уровне политическом. В целом можно говорить даже о структурной архаизации российского социума.

Для того чтобы проанализировать происходящие в настоящее время тенденции трансформации в российском обществе [10], мы обратимся к специфике изменения государства и его институтов в ходе модернизационных процессов начала 2020 года, поскольку именно данные процессы вызвали структурные и культурные трансформации, на которые следуют реакции сопротивления со стороны населения России, вынужденного приспосабливаться и адаптироваться к динамике изменений.

Элементы материальной культуры могут изменяться быстрее, чем элементы культуры духовной. То же самое можно сказать о структурном изменении - быстрые изменения на уровне социальной структуры, институциональной структуры могут в значительной степени обгонять изменения в структуре общественного сознания [11]. Такая ситуация возникает в том случае, если новые институты создаются целенаправленно и в короткие сроки, а не являются результатом длительного социально-культурного развития. В таком случае вновь созданные по внешним образцам институты могут принимать гибридные формы. Таким гибридом является современный российский политический режим. Помимо гибридности важной чертой этого режима является рассогласование между его формальной официальной стороной и неформальным содержательным наполнением.

В эпоху модерна государство превращается в сложную бюрократическую машину, функционирование которой опирается на формальные нормы и правила, принимаемые и изменяемые в рамках установленных формализованных процедур. В рамках формализованной государственной машины существует четкое распределение функций, каждый ее сегмент, как и каждый отдельный индивид, выполняющий профессиональные обязанности в рамках этой машины, выполняет четко определенную задачу. Формализация государства означает, что элементы субъективности, личных предпочтений и интересов должны быть секвестированы. Формализованная государственная машина действует не только на основе формализованных правил и процедур, но также на основе использования информации, экспертного знания об обществе.

Такие черты государственного управления, казалось бы, присутствуют и в нынешней российской его модели. Однако для российского управления характерно рассогласование между внешней формальной стороной и неформальными практиками. При этом формальная сторона выступает в качестве ширмы или декорации для неформальных связей, лежащих в основе российской модели управления. Как отмечает В. Гельман, «формальные институты, задающие рамки осуществления власти и управления, представляют собой побочный продукт распределения ресурсов внутри «вертикали власти»: они имеют значение как «правила игры» лишь в той мере, в какой способствуют (или как минимум не препятствуют) извлечению ренты» [12].

Практически все исследователи российского политического режима отмечают роль власти как ресурса для реализации личных интересов. Превращение государственной машины в механизм для обеспечения интересов политической элиты - это не только некая моральная проблема, но возвращение к устаревшим, архаичным практикам управления, когда задачей власти была не столько регуляция общественных процессов, сколько обес- 
печение своих собственных интересов за счет извлечения ресурсов из общества. В терминах М. Вебера, подобный тип господства называется патримониальным и в большей степени характерен для традиционных обществ. В настоящее время стоит обратиться к другому явлению, распространенному во многих современных обществах — неопатримониализму, который формируется в результате неудачи модернизации и соединяет черты традиционализма и современного государства.

Неопатримониальный синтез традиции (архаики) и современности меняет современные институты, которые теряют свои изначальные функции и приобретают иные. Так, партии, вместо того чтобы выражать интересы избирателей, служить посредниками между властью и обществом и обеспечивать сменяемость власти, превращаются в придаток существующей исполнительной власти, больше заинтересованной во взаимодействии с нею, чем с избирателями. Выборы в таких системах носят характер ритуала поддержки режима, их результаты нередко фальсифицируются, поэтому выборы в неопатримониальных режимах не могут обеспечить легальную смену главы государства и формирование парламента, связанного обязательствами перед обществом.

Для неопатримониальных режимов характерны следующие черты:

1) все политические, экономические и символические ресурсы власти сосредоточены в руках политического центра, который закрывает доступ к ним как и к основным ресурсам общества для всех остальных групп;

2) получение доступа к значимым ресурсам возможно только в результате договоренностей с представителями власти;

3) государство превращено в собственность политической элиты - представителей государственной власти, приватизирующих выполнение общественно значимых и управленческих функций и институций, которые служат для элиты источником дохода;

4) современные по форме политические институты служат «вместилищем» для этнических, региональных, клановых и родственных связей, которые и определяют способ функционирования этих институтов;

5) важнейшим характерным признаком неопатримониализма, согласно Эйзенштадту и другим исследователям этого феномена, является клиентелизм - система иерархических взаимоотношений между двумя акторами, подразумевающая предоставление доступа к экономическим благам, назначение на политические должности или продвижение по службе в обмен на поддержку, в том числе на выборах.

Следует отметить, что неопатримониальные режимы препятствуют формированию политических наций, а именно национальными являются современные государства. Формированию наций мешает отсутствие работающих институтов политического представительства, поэтому население не может реализовать свою политическую субъектность, проявить себя как политическая общность. Неопатримониальные режимы не формируют единую нацию, а раскалывают общество на политическое менышинство - бенефициариев сложившейся системы и большинство, полностью отчужденное от власти и лишенное возможности легально влиять на политику и развитие общества. Вместо наций неопатримониализм консервирует другие типы общностей — этнические, территориальные, клановые, которые также раскалывают единство общества, поскольку ориентируются на групповые, а не общие интересы и могут реализовать их, лишь вступая в неформальные взаимодействия с властью.

Неопатримониальные режимы, как любые формы государственной власти, нуждаются в легитимации. Поскольку сутью неопатримониализма является сращение традиционных элементов общественной и политической жизни с деформированными современными и поскольку неопатримониальные режимы не заинтересованы в изменениях, легитимацию они ищут в опоре на прошлое, верность которому оправдывает сложившееся положение дел.

Сложившийся в России политический режим не может опираться на либеральную идеологию как единственную систему идейной легитимации государства современного типа. При этом, как всякий политический режим, он стремится к самосохранению. Отсюда неизбежный крен в сторону консерватизма.

Консерватизм, в отличие от либерализма, не имеет четкого идейного ядра. Представляя собой идейно оформленную охранительную 
установку сознания, связанную с неприятием перемен, консерватизм способен использовать любой идейный материал, связанный с позитивно понимаемым прошлым. Сама по себе ориентация на прошлое уже в какойто степени архаична, поскольку общество модерна ориентируется на будущее, в чем заключается одна из его характерных черт. Современный российский консерватизм эклектичен. Он включает в себя несколько составляющих. Во-первых, это идеализированное представление о советском прошлом, во-вторых, столь же идеализированное представление о прошлом имперском, в-третьих, комплекс представлений об особом русском пути или особой российской цивилизации.

Российская архаизация показывает консервативные ориентации российской политической элиты, являющиеся не только результатом прагматического выбора, но проявлением некоторых тенденций динамики общественного сознания. Консерватизм политической элиты выступает как следствие этих тенденций. На наш взгляд, российская архаизация имеет скорее дисфункциональный характер, поскольку затрагивает не только какие-то частные аспекты жизни, но и такой системообразующий элемент общества, как политический режим. Консервативная ориентация этого режима блокирует развитие общества и является тормозом на пути дальнейших модернизационных изменений, не предлагая никаких реальных альтернатив обществу модерна, кроме поддержания существующей модели неопатримониализма с его деформированными псевдомодерными институтами, преподносимыми в качестве особой модели государственности.

Такие тенденции мы активно ощущаем в настоящий период времени, когда вся страна находится на самоизоляции, которая должна способствовать замедлению распространения новой коронавирусной инфекции. С одной стороны, нахождение населения дома, так называемая самоизоляция - это действительно одна из эффективных мер по обеспечению санитарно-эпидемиологического благополучия населения на территории Российской Федерации. Но, с другой стороны, существует множество моментов, которые превращают самоизоляцию в полную изоляцию от внешнего мира: введение электронных и бумажных про- пусков для перемещения по местности, которые ограничивают свободное перемещение населения, а также отслеживание перемещений населения посредством мобильной связи, введение штрафов за нарушения, что ограничивает свободу, тем самым может нарушать права граждан страны [13] и травмировать их социальное здоровье [14, 15]. Данные вопросы можно было бы исключить в том случае, если бы в стране был введен режим чрезвычайной ситуации, а государственные органы взяли бы на себя ряд ответственности материального характера, которые в период самоизоляции лежат на самих гражданах и вызывают отрицательные эмоции, формируют долю недоверия к государству.

Общественное развитие России и проблема пандемии. В связи с ситуацией по распространению коронавирусной инфекции президент России В.В. Путин обращался к гражданам страны несколько раз, посвящая население о принимаемых мерах в связи со сложившейся ситуацией. По данным ВЦИОМ, после обращений уровень одобрения деятельности Президента РФ составил 64,7\%, оценки работы премьер-министра и Правительства России за последнюю неделю составили $38,9 \%$ и $38,9 \%$ соответственно [16]. На наш взгляд, данные показатели говорят о том, что большая часть общества не разделяет мнения государства в связи с принятыми мерами.

Мы считаем, что реакция государства на ситуацию с коронавирусом еще раз подтверждает действие в России неопатримониального политического режима со всеми перечисленными нами характеристиками. Этот тип режима не уникален - подобные режимы возникают в ходе неудачного осуществления модернизационных изменений и имеют гибридный характер, сочетая элементы традиционности и современности. При этом современные политические институты неизбежно деформируются, вызывая недовольство со стороны населения.

Заключение. Сущность неопатримониальных режимов сводится к тому, что политическая элита концентрирует в своих руках все значимые ресурсы общества, ограничивает доступ к ним других социальных групп и блокирует любые легальные попытки смены влас- 
ти и легального политического участия населения, как и его самостоятельную гражданскую активность. Препятствуя современным формам политической деятельности и политического управления, неопатримониальные режимы нуждаются в идейной легитимации, которая неизбежно тяготеет к консерватизму, оправдывающему существующую ситуацию ссылками на традицию и отвергающему любые попытки изменений, в которых политическая элита не заинтересована. Возникновение неопатримониального режима в России является не предпосылкой, а следствием консервативных и архаизирующих тенденций в общественном сознании. Однако, сформировавшись, этот режим способствует усилению и консервации этих тенденций, блокируя тем самым процесс модернизации общества.

\section{Литература}

1. Сычева T.М. Модернизационные возможности архаики в процессе социокультурного развития общества // Манускрипт. 2019. - №8.

2. Гафиатулина Н.Х., Рачипа А.В., Самылин С.И. Информационная сетевая среда как фактор влияния на социальное здоровье российской студенческой молодежи // Гуманитарные, социально-экономические и общественные науки. - 2018. - №1. - С. 23-27.

3. Карнаушенко Л.В. Тенденции архаизации трансформирующегося российского общества и проблема криминализации // Общество и право. - 2016. - №2. - С. 10-14.

4. Ламажаа Ч.К. Архаизация общества в период социальных трансформаций // Знание. Понимание. Умение. - 2011. - №3. C. $35-42$.

5. Ахиезер А. С. Россия: критика исторического опыта (социокультурная динамика России). - Новосибирск: Сибирский хронограф, 1998. - Т. 1. От прошлого к будущему. -805 c.

6. Эйзенштадт C. Революция и преобразование обществ. Сравнительное изучение цивилизаций. - М.: Аспект Пресс, 1999.

7. Теобальд Р. Патримониализм // Прогнозис. - 2007. - №2.

8. Федотова В.Г. Архаизация в современном мире // Философские науки. 2012. 一 №5. - С. 26-36.
9. Ламажаа Ч.К. Архаизация общества в период социальных трансформаций (социально-философский анализ тувинского феномена): автореф. ... д-ра филос. н. - М., 2011.

10. Ponomarev I.E., Gafiatulina N. K., Zritineva E.I., Kasyanov V.V., et al. The influence of social justice crisis on social health and spiritual security of young students (a case study of the south of Russia). International Journal of Applied Exercise Physiology. - 2019. Vol. 8. — №2.1. - Pp. 250-257.

11. Shakhbanova M.M., Kasyanov V.V., Gafiatulina N. Kh., Gluzman I.V., Polivina M.A., Gnatyuk M.A., Ramazanov R.O. The role of trust in the formation of ethnic tolerance and social health in the modern Russian society // Revista Inclusiones. - 2019. — Vol. 6. - №2. Pp. 296-305.

12. Гельман В. Политические основания «недостойного правления» в постсоветской Евразии: наброски к исследовательской повестке дня. - СПб.: Издательство Европейского университета в Санкт-Петербурге, 2016.

13. Попов М.Ю., Самылин П.С., Самыгин С.И. К дискуссии об ограничении прав и свобод человека в условиях пандемии // Гуманитарные, социально-экономические и общественные науки. - 2020. — №4.

14. Gafiatulina N. Kh., Tarasenko L.V., Samygin S.I., Eliseeva S. Yu. Social health and perception of risks by students living in southern Russian regions (based on sociological questioning data obtained in Rostov-on-Don) // N. Kh. Gafiatulina // Health Risk Analysis. 2017. — №4. - Pp. 66-75.

15. Gafiatulina N. Kh., Vorobyev G. A., Imgrunt S. I., Samygin S. I., Latysheva A. T., Ermakova L.I., Kobysheva L. I. Social health of student youth in south Russia: analysis of the perception of socio-cultural risks (2018). Modern Journal of Language Teaching Methods. - 2018. Vol. 8. - №6. - Рp. 32-41.

16. Опрос ВЦИОМ «Рейтинги доверия политикам» [Электронный ресурс]. — URL: https://wciom.ru/index.php?id=236\&uid=10252.

\section{References}

1. Sycheva T.M. Modernizacionnye vozmozhnosti arhaiki v processe sociokul'turnogo razvitija obshhestva [Modernizing opportunities of archaics in the process of sociocultural devel- 
opment of society] // Manuskript. — 2019. №8.

2. Gafiatulina N.H., Rachipa A.V., Samygin S. I. Informacionnaja setevaja sreda kak faktor vlijanija na social'noe zdorov'e rossijskoj studencheskoj molodezhi [Information network environment as a factor of influence on the social health of Russian students] // Gumanitarnye, social'no-jekonomicheskie i obshhestvennye nauki [Humanities, socio-economic and social Sciences]. - 2018. - №1. - Pp. 23-27.

3. Karnaushenko L.V. Tendencii arhaizacii transformirujushhegosja rossijskogo obshhestva i problema kriminalizacii [Trends of archaization of the transforming Russian society and the problem of criminalization] // Obshhestvo i pravo [Society and law]. — 2016. - №2. - Pp. 10-14.

4. Lamazhaa Ch. K. Arhaizacija obshhestva $\mathrm{v}$ period social'nyh transformacij [Archaization of society in the period of social transformations] // Znanie. Ponimanie. Umenie [Knowledge. Understanding. Skill]. — 2011. — №3. Pp. 35-42.

5. Ahiezer A.S. Rossija: kritika istoricheskogo opyta (sociokul'turnaja dinamika Rossii). [Russia: criticism of historical experience (socio-cultural dynamics of Russia)]. - Novosibirsk: Sibirskij hronograf, 1998. — Vol. 1. Ot proshlogo $\mathrm{k}$ budushhemu [From the past to the future]. $-805 \mathrm{p}$.

6. Jejzenshtadt $S$. Revoljucija i preobrazovanie obshhestv. Sravnitel'noe izuchenie civilizacij [Revolution and transformation of societies. Comparative study of civilizations]. Moscow: Aspekt Press, 1999.

7. Teobal'd R. Patrimonializm [Patrimonialism] // Prognozis. - 2007. — №2.

8. Fedotova V.G. Arhaizacija v sovremennom mire [Archaization in the modern world] // Filosofskie nauki [Philosophical Sciences]. 2012. - №5. - Pp. 26-36.

9. Lamazhaa Ch. K. Arhaizacija obshhestva $\mathrm{v}$ period social'nyh transformacij (social'nofilosofskij analiz tuvinskogo fenomena): avtoref.... d-ra filos. n. [Archaization of society in the period of social transformations (socio-philosophical analysis of the Tuva phenomenon): Dr. Sci. (Psychology) diss.]. — Moscow, 2011.
10. Ponomarev I. E., Gafiatulina N. K., Zritineva E.I., Kasyanov V. V., et al. The influence of social justice crisis on social health and spiritual security of young students (a case study of the south of Russia). International Journal of Applied Exercise Physiology. — 2019. - Vol. 8. №2.1. - Pp. 250-257.

11. Shakhbanova M.M., Kasyanov V.V., Gafiatulina N. Kh., Gluzman I.V., Polivina M.A., Gnatyuk M.A., Ramazanov R.O. The role of trust in the formation of ethnic tolerance and social health in the modern Russian society // Revista Inclusiones. - 2019. - Vol. 6. - №2. Pp. 296-305.

12. Gel'man $V$. Politicheskie osnovanija «nedostojnogo pravlenija» v postsovetskoj Evrazii: nabroski $\mathrm{k}$ issledovatel'skoj povestke dnja [Political foundations of «unworthy governance» in post-Soviet Eurasia: outline for a research agenda]. - Saint-Petersburg: Izdatel'stvo Evropejskogo universiteta v Sankt-Peterburge, 2016.

13. Popov M. Ju., Samygin P.S., Samygin S.I. K diskussii ob ogranichenii prav i svobod cheloveka $\mathrm{v}$ uslovijah pandemii [To the discussion on the restriction of human rights and freedoms in the context of a pandemic] // Gumanitarnye, social'no-jekonomicheskie i obshhestvennye nauki [Humanities, socio-economic and social Sciences]. — 2020. — №4.

14. Gafiatulina N. Kh., Tarasenko L.V., Samygin S. I., Eliseeva S. Yu. Social health and perception of risks by students living in southern Russian regions (based on sociological questioning data obtained in Rostov-on-Don) // N. Kh.Gafiatulina // Health Risk Analysis. 2017. - №4. - Pp. 66-75.

15. Gafiatulina N. Kh., Vorobyev G.A., Imgrunt S. I., Samygin S. I., Latysheva A. T., Ermakova L. I., Kobysheva L. I. Social health of student youth in south Russia: analysis of the perception of socio-cultural risks (2018). Modern Journal of Language Teaching Methods. - 2018. Vol. 8. - №6. - Pp. 32-41.

16. Opros VCIOM «Rejtingi doverija politikam» [VTSIOM poll «Trust Ratings for politicians»] [Jelektronnyj resurs]. — URL: https:// wciom.ru/index.php?id=236\&uid=10252. 


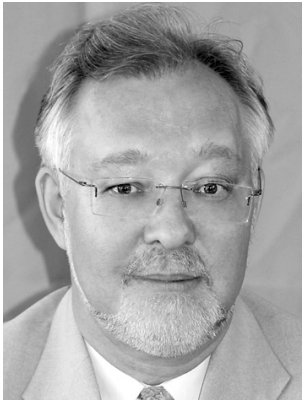

344023, г. Ростов-на-Дону, пр. Ленина, 92

92 Lenina av., 344023, Rostov-on-Don, Russia

E-mail: otdel_praktiki_dpk@mail.ru_
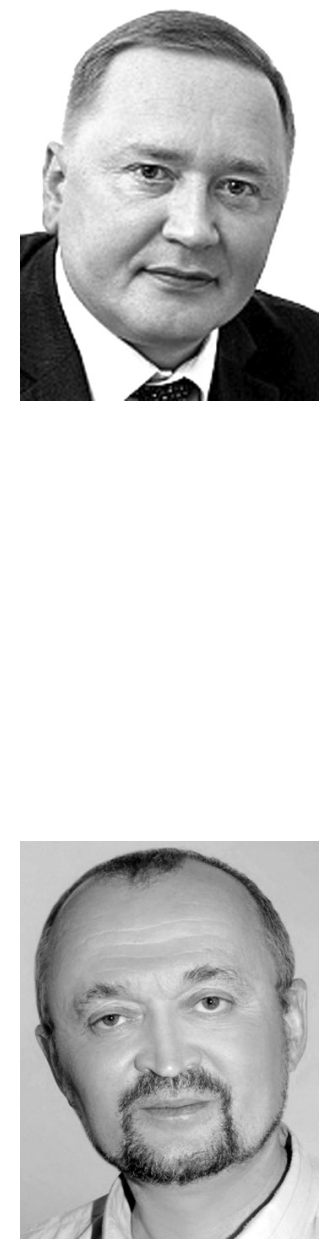
Pedagogical College. gies, Pyatigorsk State University.

357532, г. Пятигорск, пр. Калинина, 9

9 Kalinina av., 357532, Pyatigorsk, Russia

E-mail: vorobyev@pgu.ru верситета (РИНХ).
Алексеено Иван Николаевич - доктор философских наук, заместитель директора по учебно-производственной работе Донского педагогического колледжа.

Alekseenko Ivan Nickolaevich - Doctor of Philosophical Sciences, Deputy Director for Training and Productive Work, Don

Воробьёв Геннадий Александрович - доктор философских наук, доцент, директор Института дистанционного обучения и развития информационно-коммуникационных технологий Пятигорского государственного университета.

Vorobiev Gennady Alexandrovich - Doctor of Philosophical Sciences, Associate Professor, Director, Institute for Distance Learning and Development of Information and Communication Technolo-

Самыгин Сергей Иванович - профессор, доктор социологических наук, профессор кафедры управления персоналом и социологии Ростовского государственного экономического уни-

Samygin Sergey Ivanovich - Professor, Doctor of Sociological Sciences, Professor, Department of Personnel Management and Sociology, Rostov State University of Economics (RSUE).

344002, г. Ростов-на-Дону, ул. Большая Садовая, 69

69 Bolshaya Sadovaya str., 344002, Rostov-on-Don, Russia

E-mail: darya.maksimovich@gmail.com 